\title{
GPER-mediated proliferation and estradiol production in breast cancer-associated fibroblasts
}

\author{
Haojun Luo, Guanglun Yang ${ }^{1}$, Tenghua $\mathrm{Yu}^{1}$, Shujuan Luo ${ }^{2}$, Chengyi $\mathrm{Wu}^{1}$, Yan Sun ${ }^{3}$, \\ Manran Liu ${ }^{3}$ and Gang Tu' \\ Department of Breast and Thyroid Surgery, the Second Affiliated Hospital of Chongqing Medical University, \\ Chongqing 400010, China \\ ${ }^{1}$ Department of Endocrine and Breast Surgery, the First Affiliated Hospital of Chongqing Medical University, \\ No. 1 You-Yi Road, Yu-zhong District, Chongqing 400016, China \\ ${ }^{2}$ Department of Gynecology and Obstetrics, Chongqing Health Center for Women and Children, \\ Chongqing 400010, China \\ ${ }^{3}$ Key Laboratory of Laboratory Medical Diagnostics, Chinese Ministry of Education, Chongqing Medical University, \\ No. 1 Yi-Xue-Yuan Road, Yu-zhong District, Chongqing 400016, China
}

Correspondence should be addressed to G Tu or M Liu Emails tugang68@126.com or mliu-hncq@hotmail.com

\begin{abstract}
Cancer-associated fibroblasts (CAFs) are crucial co-mediators of breast cancer progression. Estrogen is the predominant driving force in the cyclic regulation of the mammary extracellular matrix, thus potentially affecting the tumor-associated stroma. Recently, a third estrogen receptor, estrogen (G-protein-coupled) receptor (GPER), has been reported to be expressed in breast CAFs. In this study, GPER was detected by immunohistochemical analysis in stromal fibroblasts of $41.8 \%$ (59/141) of the primary breast cancer samples. GPER expression in CAFs isolated from primary breast cancer tissues was confirmed by immunostaining and RT-PCR analyses. Tamoxifen (TAM) in addition to $17 \beta$-estradiol $\left(E_{2}\right)$ and the GPER agonist $G 1$ activated GPER, resulting in transient increases in cell index, intracellular calcium, and ERK1/2 phosphorylation. Furthermore, TAM, $E_{2}$, and $G 1$ promoted CAF proliferation and cell-cycle progression, both of which were blocked by GPER interference, the selective GPER antagonist G15, the epidermal growth factor receptor (EGFR) inhibitor AG1478, and the ERK1/2 inhibitor U0126. Importantly, TAM as well as $G 1$ increased $E_{2}$ production in breast CAFs via GPER/EGFR/ERK signaling when the substrate of $E_{2}$, testosterone, was added to the medium. GPER-induced aromatase upregulation was probably responsible for this phenomenon, as TAM- and G1-induced CYP19A1 gene expression was reduced by GPER knockdown and G15, AG1478, and U0126 administration. Accordingly, GPER-mediated CAF-dependent estrogenic effects on the tumor-associated stroma are conceivable, and CAF is likely to contribute to breast cancer progression, especially TAM resistance, via a positive feedback loop involving GPER/EGFR/ERK signaling and $E_{2}$ production.
\end{abstract}
Key Words
- CAF
- GPER
- tamoxifen resistance
- breast cancer

Endocrine-Related Cancer (2014) 21, 355-369

\section{Introduction}

The local microenvironment plays an important and intricate role in the progression of breast cancer. Increasing evidence suggests that activated stroma is a prerequisite for tumor formation (Barcellos-Hoff \& Ravani 2000), the progression of ductal carcinoma in situ to the invasive stage (Hu et al. 2008), and the metastatic process http://erc.endocrinology-journals.org DOI: 10.1530/ERC-13-0237
(C) 2014 The authors Published by Bioscientifica Ltd Printed in Great Britain

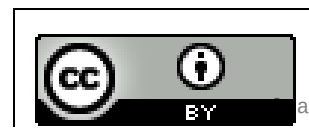

This work is licensed under a Creative Commons Attribution 3.0 Unported License. 
(Karnoub et al. 2007). However, stromal cells have been revealed to inhibit the early stages of tumor progression, but to promote progression at the later stages (Proia \& Kuperwasser 2005, Cirri \& Chiarugi 2012). Importantly, the tumor:stroma ratio and the stroma type in primary breast cancer have been reported to be associated with patient survival including recurrence, distant metastasis, and death (de Kruijf et al. 2011, Ahn et al. 2012).

The cancer stroma is composed of diverse cell types including endothelial cells, immune cells, and fibroblasts, which are the most abundant cell type in breast cancer (Xing et al. 2010, Cirri \& Chiarugi 2012). Considering that 'tumors are wounds that do not heal', $~ 80 \%$ of fibroblasts in breast cancer stroma share some similarities, such as $\alpha$-smooth muscle actin (SMA) expression, with myofibroblasts being activated during wound healing (Sappino et al. 1988). These fibroblasts acquire an aggressive phenotype and contribute to tumor growth, angiogenesis, invasion, and metastasis directly or indirectly by paracrine action of various growth factors, cytokines, proteases, and hormones including estrogens (Karnoub et al. 2007, Hu et al. 2008, Yamaguchi \& Hayashi 2009, Xing et al. 2010, Cirri \& Chiarugi 2012). Accordingly, these activated fibroblasts in the tumor stroma are designated cancer-associated fibroblasts (CAFs) and are recognized as co-mediators of tumor progression rather than as merely bystanders.

Estrogen is well recognized as a mitogen for breast cancer cells. Traditionally, estrogenic effects have been ascribed to the nuclear estrogen receptors (ER $\alpha$ and ER $\beta$ ) that function as transcription factors binding to the regulatory response elements in the promoters of target genes (Pietras et al. 2005). However, estrogen also triggers rapid cellular events that are independent of transcriptional activity (Pietras \& Szego 1975, Filardo et al. 2000, Pietras et al. 2005, Revankar et al. 2005). At present, the third ER, estrogen (G-protein-coupled) receptor (GPER) (also referred as GPR30), is largely accepted as the mediator of these 'rapid', 'nongenomic' effects (Prossnitz \& Maggiolini 2009, Prossnitz \& Barton 2011). GPER was identified in the late 1990s as a seven-transmembrane G-protein-coupled receptor (GPCR), belonging to a superfamily of membrane receptors traditionally recognized to mediate rapid signaling by modulating second messengers and kinase pathways (Owman etal. 1996, Carmeci et al. 1997, O'Dowd etal. 1998). In 2000 , the $17 \beta$-estradiol $\left(\mathrm{E}_{2}\right)$-triggered rapid activation of ERK1/2 in breast cancer cells was found to correlate with GPER (GPER1) expression by Filardo et al. (2000). In 2002, the same group reported that GPER mediated the transactivation of the epidermal growth factor receptor (EGFR) to the MAPK signaling axis in response to $\mathrm{E}_{2}$ (Filardo 2002).
In addition, GPER was reported to be associated with the modulation of calcium $\left(\mathrm{Ca}^{2+}\right)$, cAMP, and phosphatidylinositol 3-kinase (PI3K) in the subsequent years (Filardo et al. 2002, Pietras et al. 2005, Revankar et al. 2005). Although the transcriptional effect of estrogen is almost exclusively correlated with ER $\alpha$, GPER-triggered rapid signaling events have also been observed to regulate gene expression. Multiple genes, such as FOS, BCL2, cyclin D1, connective tissue growth factor $(C T G F)$, and early growth response 1 (EGR1), have been included in the GPER-targeted gene list (Prossnitz \& Maggiolini 2009, Madeo \& Maggiolini 2010, Vivacqua et al. 2012). Accordingly, GPER has been shown to be involved in the proliferation, migration, chemoresistance, and metastasis of breast cancer (Wang et al. 2010).

Estrogen plays a critical role in the development and cyclic regulation of the mammary gland, which is composed not only of epithelium but also of stroma (Arendt et al. 2010). This raises the logical question of whether estrogen affects breast-cancer-associated stroma. Intriguingly, accumulating evidence related to GPER expression and its proliferative role in breast CAFs has been reported (Madeo \& Maggiolini 2010, Pupo et al. 2012, Vivacqua et al. 2012). Madeo \& Maggiolini (2010) revealed that GPER is exclusively expressed as an ER in mammary CAFs and induces the expression of C-FOS, cyclin D1, and CTGF in response to $\mathrm{E}_{2}$, confirmed at both the mRNA and the protein level, resulting in the promotion of proliferation. GPER has also been shown to be involved in the growth and migration stimulated by $\mathrm{E}_{2}$, 4-hydroxytamoxifen, and bisphenol $\mathrm{A}$ in breast CAFs (Pupo et al. 2012, Vivacqua et al. 2012). Thus, it can be proposed that estrogen, as an important factor in the breast cancer local microenvironment, is involved in cancer progression in a GPER-mediated CAF-dependent model.

Interestingly, tamoxifen (TAM), a selective ER modulator (SERM) targeting $\mathrm{ER} \alpha$, and its metabolite 4-hydroxytamoxifen have been recognized as agonists of GPER (Prossnitz \& Barton 2011, Vivacqua et al. 2012), indicating a potential role of GPER in breast cancer TAM resistance. In clinical specimens, the co-expression of ER $\alpha$ (ESR1) and GPER has been found in $\sim 40 \%$ of the primary breast cancer cases and GPER expression, as an independent unfavorable factor, has been found to correlate with relapse-free survival in patients treated with TAM (Filardo et al. 2006, Ignatov et al. 2011). In vitro, TAM has been reported to enhance proliferation via sensitivity-enhanced GPER/EGFR/MAPK signaling in TAM-resistant MCF-7 cells, and knockdown of GPR3O in MCF-7 cells has been shown to decrease the proliferation of cells exposed to TAM (Ignatov et al. 2010, Peralta et al. 2010). Furthermore, a TAM analog has been demonstrated to promote

Published by Bioscientifica Ltd 
endometrial cell proliferation and aromatase gene expression, implying that GPER plays a positive role in estrogen production (Lin et al. 2009).

In the present study, we demonstrated that GPER is expressed in the stromal fibroblasts of primary breast cancer tissues and CAFs isolated from tumor tissues. $\mathrm{E}_{2}$, the GPER agonist G1 (1-(4-(6-bromobenzo[1,3]dioxol5-yl)-3a, 4,5,9b-tetrahydro-3H-cyclopenta[c]quinolin-8yl)-ethanone, 1-[(3aS,4R,9bR-rel)-4-(6-bromo-1,3-benzodioxol-5-yl)-3a,4,5,9b-tetrahydro-3H-cyclopenta[c]quinolin-8-yl]-ethanone), and TAM activated GPER in breast CAFs and promoted proliferation and cell-cycle progression via the GPER/EGFR/ERK axis. Moreover, TAM and G1 induced CYP19A1 gene expression and increased $\mathrm{E}_{2}$ production, also via the GPER/EGFR/ERK pathway, providing novel insights into the estrogenic effects on the breast cancer microenvironment and the induction of TAM resistance in a CAF-dependent manner.

\section{Subjects and methods}

\section{Chemicals}

$\mathrm{E}_{2}$, TAM, the GPER agonist G1, and the GPER antagonist G15 (4-(6-bromo-benzo[1,3]dioxol-5-yl)-3a,4,5,9b-tetrahydro-3H-cyclopenta[c]quinoline) were purchased from Sigma-Aldrich. The EGFR inhibitor AG1478 (AG), the ERK1/2 inhibitor U0126, and the PI3K inhibitor Wortmannin (WM) were purchased from Millipore (Temecula, CA, USA). All chemicals were solubilized in DMSO.

\section{Clinical specimens}

A total of 141 archival paraffin-embedded, formalin-fixed breast tumor tissue samples were obtained from the Clinical Diagnostic Pathology Center of Chongqing Medical University (Chongqing, China). All patients had undergone surgery at the First Affiliated Hospital of Chongqing Medical University during the period ranging from January 2009 to December 2010. The samples of patients treated with neoadjuvant chemotherapy were excluded. Diagnosis was confirmed by immunohistochemical assays for $\mathrm{ER} \alpha$, progestin receptor, and human EGFR2 by the same center. The investigation was approved by the ethics committee of Chongqing Medical University.

\section{Immunohistochemistry}

Commercial rabbit anti-GPER polyclonal antibody (Abcam, Cambridge, MA, USA) was used in immunohistochemical staining as described previously (Filardo et al. 2006). Briefly, tissue samples were deparaffinized and heated at $95^{\circ} \mathrm{C}$ in $0.1 \mathrm{~mol} / \mathrm{l}$ sodium citrate $(\mathrm{pH} 6.0)$ for antigen recovery, and endogenous peroxidase activity was quenched with $3 \% \mathrm{H}_{2} \mathrm{O}_{2}$. Nonspecific binding sites were blocked by incubation in $5 \%$ goat serum solution for $30 \mathrm{~min}$ at $37^{\circ} \mathrm{C}$. Slides were exposed to primary antibody (1:200) for $2 \mathrm{~h}$ at $37^{\circ} \mathrm{C}$. Sections were incubated in HRP-conjugated goat anti-rabbit IgG for $20 \mathrm{~min}$ at $37^{\circ} \mathrm{C}$. Diaminobenzidine was added as a substrate. Nuclei were counterstained using Mayer's modified hematoxylin.

GPER expression in stromal fibroblasts and epithelium was evaluated separately. A specimen was considered to be GPER-positive when distinct staining of at least 10\% of the stromal fibroblasts was observed (Hoshino et al. 2011). GPER expression in tumor cells was evaluated as described previously (Filardo et al. 2006).

\section{Isolation, identification, and immortality of mammary fibroblasts and cell culture}

Fibroblasts were isolated as described previously (Zhao et al. 2012). Briefly, tumor tissue samples and coupled grossly normal breast tissue samples (at least $2 \mathrm{~cm}$ from the tumor margin) resected during surgery were washed with sterile PBS containing antibiotics $(100 \mathrm{U} / \mathrm{ml}$ penicillin, $100 \mu \mathrm{g} / \mathrm{ml}$ streptomycin, and $50 \mu \mathrm{g} / \mathrm{ml}$ gentamicin) and were then minced with scissors in a culture dish. After digestion with $0.1 \%$ collagenase type I (Sigma) at $37^{\circ} \mathrm{C}$ for $8-12 \mathrm{~h}$, the suspensions were carefully pipetted up and down in the culture medium. The suspensions were centrifuged ( $1200 \boldsymbol{g}$ for $5 \mathrm{~min}$ ) and washed with DMEM to remove the fat and tissue debris. The suspension was maintained in DMEM containing 10\% fetal bovine serum (FBS) for $\sim 2$ days to allow cell attachment. The most adherent cells (fibroblasts) were further maintained in DMEM containing 10\% FBS. The investigation was approved by the Local Ethics Committee, and informed consent was obtained from the patients.

CAFs were identified by immunostaining for $\alpha$-SMA and fibroblast active protein (FAP), as well as by evaluation of cell morphology (Zhao et al. 2012). Fibroblast populations with CAF purity exceeding $85 \%$ were used as CAFs in related experiments. The primary CAFs were then immortalized with the human telomerase catalytic subunit (hTERT; from AddGene, Cambridge, MA, USA) for subsequent experiments. MCF-7 cells were maintained in DMEM with phenol red, supplemented with $10 \%$ FBS.

Published by Bioscientifica Ltd. 


\section{Immunofluorescence}

Immunofluorescent staining was utilized to identify CAFs and ER expression following a previously described protocol (Zhao et al. 2012). Briefly, $10^{5}$ cells were grown on coverslips for $24 \mathrm{~h}$ and fixed with $4 \%$ paraformaldehyde, treated with $0.1 \%$ Triton X-100, and blocked with $5 \%$ goat serum. The cells were then incubated overnight at $4{ }^{\circ} \mathrm{C}$ with primary antibodies targeting $\alpha$-SMA, FAP, and GPER (Abcam) and ER $\alpha$ and ER $\beta$ (ZSGB-BIO, Beijing, China); all dilutions were 1:150. After washing with PBS, the cells were stained with a FITC-labeled goat anti-rabbit secondary antibody (1:100; Zhongshan Golden Bridge, Beijing, China) for $10 \mathrm{~min}$ and 4',6-diamidino-2-phenylindole (DAPI) for $5 \mathrm{~min}$. Immunofluorescent images were obtained using a Nikon Eclipse 80i microscope (Tokyo, Japan).

\section{Measurement of intracellular $\mathrm{Ca}^{2+}$ mobilization}

Changes in intracellular $\mathrm{Ca}^{2+}$ mobilization were measured using the $\mathrm{Ca}^{2+}$-sensitive fluorescent probe Fluo-3/AM (1-[2-Amino-5-(2,7-dichloro-6-hydroxy-3-oxo9-xanthenyl)phenoxy]-2-(2-amino-5-methylphenoxy)ethane- $N, N, N^{\prime}, N^{\prime}$-tetraacetic acid, pentaacetoxymethyl ester) (Beyotime, Haimen, Jiangsu, China). Cells were seeded in $35 \mathrm{~mm}$ dishes for attachment in normal medium for $24 \mathrm{~h}$. For labeling intracellular $\mathrm{Ca}^{2+}$, the cells were incubated in $500 \mu \mathrm{l}$ DMEM with $2.5 \mathrm{M}$ Fluo-3/AM at $37^{\circ} \mathrm{C}$ in the dark for $1 \mathrm{~h}$. The cells were then washed and stored in phenol-free DMEM without Fluo-3/AM for $30 \mathrm{~min}$ at $37^{\circ} \mathrm{C}$. Fluorescence (excitation $488 \mathrm{~nm}$ and emission $543 \mathrm{~nm}$ ) was determined using a Leica TCS SP2-laser scanning spectral confocal microscope (Mannheim, Germany). Scanning was performed every $3 \mathrm{~s}$ and baseline fluorescence was recorded for $15 \mathrm{~s}$. The test compounds diluted in assay buffer were then added, and fluorescence intensity was monitored for $150 \mathrm{~s}$. Data were quantified and analyzed using Image J Software (National Institutes of Health, Bethesda, MD, USA). Background fluorescence was subtracted, and fluorescence intensity is expressed relative to baseline values.

\section{Dynamic monitoring of GPCR activation}

The cellular response to GPCR stimulation was monitored using an RTCA DP instrument (xCELLigence system, Roche; Leonard et al. 2013). The RTCA DP Station was maintained in a humidified cell-culture incubator under normal culture conditions throughout the experiments. Background impedance was measured with
$100 \mu \mathrm{l}$ of cell-culture medium/well. CAFs $\left(2.0 \times 10^{4} /\right.$ well $)$ were plated, and the final volume of the cell-culture medium was adjusted to $200 \mu \mathrm{l} /$ well. To allow equal distribution of cells, E-Plates 16 containing cells were pre-incubated for $30 \mathrm{~min}$ at room temperature. Subsequently, the plates were transferred to the RTCA DP Station inside the incubator and cultured overnight. Impedance was routinely recorded at 15-min intervals to monitor cell-culture conditions. After the administration of GPCR agonists, impedance was monitored at intervals of 1-3 min for at least $2 \mathrm{~h}$. Results are expressed as cell index normalized to the time point of compound administration.

\section{siRNA transfection}

CAFs $\left(4 \times 10^{5}\right)$ were seeded into $25 \mathrm{~cm}^{2}$ culture flasks in $2 \mathrm{ml}$ of growth medium and grown to $80 \%$ confluence before transfection. GPER-specific siRNA (siGPER) or nonspecific control siRNA (scrambled siRNA) (Genechem, Shanghai, China) were transiently transfected using Lipofectamine 2000 reagent following the manufacturer's instructions. The target sequences for GPR30 siRNA were 5'-GCUGUACAUUGAGCAGAAATT-3' (A) and 5'-UUUCUGCUCAAUGUACAGCTT-3' (B). The control siRNA sequence that did not match any known human cDNA was 5'-AAGGTGTCAGAAACTGACGAT-3'. GPER protein expression was analyzed by western blotting after transfection.

\section{Real-time RT-PCR}

Total RNA was isolated from cells using TRIzol (Invitrogen) according to the manufacturer's protocol. RNA was reverse-transcribed using the RT2 First Strand Kit and MMLV-RT (Takara, Dalian, China). The cDNA was subjected to real-time PCR amplification using genespecific primers and $2 \times$ Brilliant II SYBR Green QPCR Master Mix (Invitrogen, La Jolla, CA, USA) as described previously (Zhao et al. 2012). Primer sequences are listed in Table 1. Specific gene expression was calculated using the comparative $2^{-\triangle \Delta C t}$ method with GAPDH as the calibrator.

\section{Proliferation assay}

Cells were seeded into 96-well plates $\left(5 \times 10^{3}\right.$ cells/well $)$ and cultured for $24 \mathrm{~h}$ in normal growth medium. The medium was then replaced with phenol red-free and serum-free medium (DMEM; Gibco), and the cells were cultured for a further $24 \mathrm{~h}$ before the addition of $\mathrm{E}_{2}, \mathrm{G} 1$,

Published by Bioscientifica Ltd. 
Table 1 Real-time PCR primer sequences for genes analyzed

\begin{tabular}{l} 
Genes \\
\hline GPER \\
ER $\alpha$ \\
ER $\beta(E S R 2)$ \\
CYP19A1 \\
GAPDH
\end{tabular}

\begin{tabular}{l} 
Forward \\
\hline TGGGGAAGAGGCCACCA \\
AGGCCAAATTCAGATAATCGAC \\
AGCTCAGCCTGTTCGACCAAG \\
GGGCACATCCTCAATACCAG \\
GAAGGTGAAGGTCGGAGTC
\end{tabular}

Reverse

CGT GGAGCTGCTCACTCTCTG

GAAGCATAGTCATTGCACAC

ACGCATTTCCCCTCATCCCT

CAGAAGGGTCAACACGTCCA

GAAGATGGTGATGGGATTTC

or TAM with or without G15, AG, U0126, and WM pretreatment at the designated concentration. The cells were further cultured in phenol red-free DMEM containing $2.5 \%$ dextran-coated charcoal-treated FBS. Cell viability was evaluated using Cell Counting Kit-8 (Beyotime) after $72 \mathrm{~h}$.

\section{Cell-cycle assay}

Cells were seeded in six-well plates $\left(2 \times 10^{5}\right.$ cells/well $)$ and cultured for $24 \mathrm{~h}$. Cell growth was synchronized in phenol red-free and serum-free medium for $24 \mathrm{~h}$ before the addition of $E_{2}, G 1$, or TAM with or without G15, AG, U0126, and $\mathrm{WM}$ pretreatment at the designated concentration for $24 \mathrm{~h}$. Cell-cycle distribution was analyzed by flow cytometry as described previously (Liu et al. 2010). Briefly, treated cells were harvested and fixed with $70 \%$ ethanol at $4{ }^{\circ} \mathrm{C}$ for $1 \mathrm{~h}$ and then resuspended in $1 \mathrm{ml} \mathrm{PBS}$ containing propidium iodide (PI; $50 \mu \mathrm{g} / \mathrm{ml})$ and RNase A $(0.1 \mathrm{mg} / \mathrm{ml})$ and incubated at $37^{\circ} \mathrm{C}$ for $30 \mathrm{~min}$. Finally, the cells $\left(10^{5}\right.$ cells/ analysis) were analyzed by flow cytometry (FACSVantage SE, BD, Franklin Lakes, NJ, USA), and cell-cycle distribution was determined by PI staining of DNA content.

\section{Immunoblotting}

Cells were stimulated with $\mathrm{E}_{2}$, G1, or TAM for 15 min with or without G15, AG, U0126, and WM pretreatment. Western blotting was then performed as described previously (Liu et al. 2010). Briefly, cell lysates were harvested in a cell lysis buffer (Boster, Wuhan, China), dissolved in 9\% SDS-PAGE buffer, and subjected to western blotting using primary detection antibodies against total or phosphorylated ERK1/2 (diluted 1:1000; BioWorld, St Louis Park, MN, USA) and GPER. Membranes were incubated overnight at $4{ }^{\circ} \mathrm{C}$ before incubation with the appropriate HRP-conjugated secondary antibodies. Immunodetection was conducted using the enhanced chemiluminescence system (Amersham Pharmacia Biotech). Optimal density was analyzed using Image J Software, and results were expressed as fold change relative to the control.

\section{$E_{2}$ production assay}

Cells were seeded in six-well plates $\left(2 \times 10^{6}\right.$ cells/well $)$ and cultured to $50 \%$ confluence. Testosterone was added at the appropriate concentration. The administration of G1 or TAM was done $1 \mathrm{~h}$ later with or without G15, AG, U0126, and WM pretreatment. The cells were cultured for $48 \mathrm{~h}$, and the medium was harvested for $\mathrm{E}_{2}$ detection using the Access $\mathrm{E}_{2}$ Immunoassay System (Beckman Coulter, Brea, CA, USA) in the Endocrinology Laboratory, the First Affiliated Hospital of Chongqing Medical University (Chongqing, China).

\section{Statistical analysis}

Statistical analysis was carried out using the SPSS System 17.0 for Windows. Associations between GPER expression and clinicopathological determinants were evaluated using the $\chi^{2}$ test and the Fisher's exact test (for nominal variables) as appropriate. For measurement data, Student's $t$-test or ANOVAs followed by the Student-Newman-Keuls multiple comparison tests were used to evaluate differences between the subgroups. Two-tailed $P$ values $\leq 0.05$ were considered to be statistically significant.

\section{Results}

\section{GPER is expressed in stromal fibroblasts of primary breast cancer tissues}

All the 141 tumor samples included in this study were invasive ductal carcinoma samples from patients who had not received neoadjuvant chemotherapy. The characteristics of patients and tumors are summarized in Table 2. Stromal fibroblasts were identified as large spindle-shaped mesenchymal cells with stress fibers and well-developed fibronexus based on previously reported descriptions (Hoshino et al. 2011). Antibody specificity was validated in SKBr3, MDA-MB-468, MCF-7, MDA-MB-435, and MDA-MB-231 breast cancer cells, which are known to express GPER at varying levels (Supplementary Fig. 1, see section on supplementary data given at the end of

Published by Bioscientifica Ltd 
Table 2 Patient and tumor characteristics

\begin{tabular}{|c|c|c|c|}
\hline & \multirow[b]{2}{*}{ No. of patients (\%) } & \multicolumn{2}{|c|}{ GPER positivity } \\
\hline & & Parenchymal & Stromal \\
\hline Total & 141 & 94 & 59 \\
\hline Age (mean \pm s.D.) & $53.0 \pm 10.9$ & $53.6 \pm 10.9$ & $53.3 \pm 11.8$ \\
\hline \multicolumn{4}{|c|}{ Menstruation status } \\
\hline Estrous & $52(36.9)$ & 34 & 20 \\
\hline Postmenopause & $89(63.1)$ & 60 & 39 \\
\hline Tumor size & $25.6 \pm 13.1$ & $24.4 \pm 10.9$ & $26.4 \pm 14.8$ \\
\hline$<2 \mathrm{~cm}$ & $58(41.1)$ & 42 & 22 \\
\hline $2-5 \mathrm{~cm}$ & $75(53.2)$ & 47 & 32 \\
\hline$>5 \mathrm{~cm}$ & $8(5.7)$ & 5 & 5 \\
\hline \multicolumn{4}{|l|}{$\mathrm{pN}^{(n=134)}$} \\
\hline 0 & $72(51.1)$ & 50 & 29 \\
\hline 1 & $28(19.9)$ & 19 & 13 \\
\hline 2 & $22(15.6)$ & 12 & 11 \\
\hline 3 & $12(8.5)$ & 8 & 5 \\
\hline \multicolumn{4}{|l|}{ Staging } \\
\hline I & $35(24.8)$ & 25 & 14 \\
\hline II & $61(43.3)$ & 42 & 25 \\
\hline III & $38(27.0)$ & 22 & 19 \\
\hline$x$ & $7(5.0)$ & 5 & 1 \\
\hline \multicolumn{4}{|l|}{ Histological grade } \\
\hline 1 & $25(17.7)$ & 15 & 12 \\
\hline 2 & $94(66.7)$ & 64 & 36 \\
\hline 3 & $22(15.6)$ & 15 & 11 \\
\hline NPI $(n=134)$ & $4.2 \pm 1.2$ & $4.1 \pm 1.2$ & $4.3 \pm 1.3$ \\
\hline 1 & $13(9.2)$ & 6 & 7 \\
\hline 2 & $36(26.9)$ & 29 & 13 \\
\hline 3 & $63(44.7)$ & 41 & 26 \\
\hline 4 & 22 (15.6) & 13 & 12 \\
\hline \multicolumn{4}{|l|}{ ER } \\
\hline+ & $79(56.0)$ & $58^{*}$ & 32 \\
\hline- & $62(44.0)$ & 36 & 27 \\
\hline \multicolumn{4}{|l|}{ PR } \\
\hline+ & $58(41.1)$ & 40 & 24 \\
\hline- & $83(58.9)$ & 54 & 35 \\
\hline \multicolumn{4}{|l|}{ HER2 } \\
\hline- & 67 (47.5) & 45 & 29 \\
\hline+ & $20(14.2)$ & 13 & 10 \\
\hline++ & $31(22.0)$ & 24 & 13 \\
\hline+++ & 23 (16.3) & 12 & 7 \\
\hline
\end{tabular}

this article). GPER was positively stained in a cytoplasmic pattern, and 59 tumor samples (41.8\%) were considered to be stromal fibroblast GPER-positive based on distinct staining of $10 \%$ or more of the fibroblasts (Table 2). Twothirds $(66.7 \%)$ of the samples exhibited positive tumor cell staining of varying density. Varying degrees of epithelial GPER expression were observed (Fig. 1A, B, C, D, E, F, G and H). However, a significant association was detected between stromal and epithelial GPER expression (data not shown). Interestingly, positive GPER staining was also observed in arterial smooth muscle cells and endothelial cells (Fig. 1I and J), which are considered to be the origins of CAFs (Zeisberg et al. 2007).
Correlations between GPER expression in stromal fibroblasts, as well as in carcinoma cells, and clinicopathological parameters of breast cancer are summarized in Table 2. GPER staining in stromal fibroblasts did not correlate with the determinants analyzed. However, epithelial GPER expression was exclusively associated with ER $\alpha$ expression.

\section{GPER is expressed in CAFs isolated from} primary breast cancer tissues

Fibroblasts isolated from primary breast cancer tissues were observed to be myofibroblasts with both a spindle-shaped

Published by Bioscientifica Ltd. 

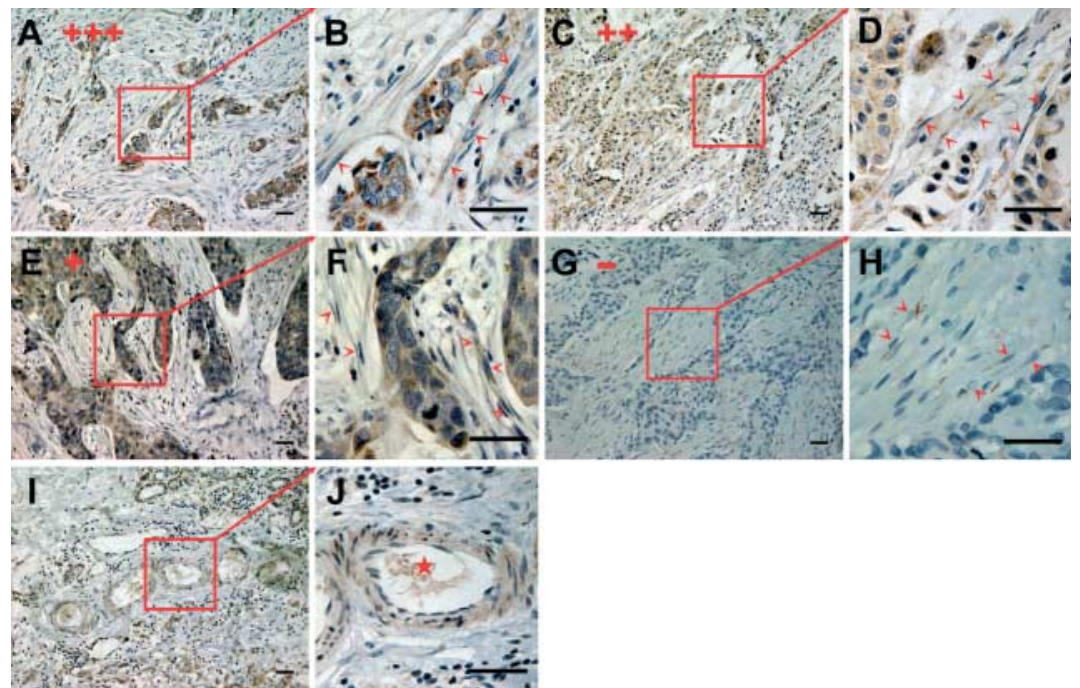

Figure 1

Representative cases of archival paraffin-embedded breast tumor tissue samples immunostained with GPER. GPER was positively stained in stromal fibroblasts (arrows indicate fibroblasts stained by GPER in (B), (D), (F) and $(\mathrm{H})$ ) with varying staining density in epithelium. According to the

and a stellate morphology. Mammary CAFs were identified by positive staining for $\alpha$-SMA and FAP as described previously (Zhao et al. 2012; Fig. 2A).

GPER expression was confirmed by immunostaining of primary and immortalized (CAF-hTERT) breast CAFs, using MCF-7 cells as positive controls (Fig. 2A). Moreover, we detected GPER mRNA by real-time RT-PCR in six cases of primary CAFs and immortalized CAFs (Fig. 2B). The level of GPER expression in primary CAFs ranged from 0.08 - to 0.98 fold (mean, 0.42-fold) relative to the expression detected in MCF-7 cells. However, GPER expression in CAF-hTERT cells was half (0.49-fold) of that detected in MCF-7 cells. Considering that GPER was identified as a GPCR and overexpressed in MCF-7 cells (Carmeci et al. 1997), GPER expression in breast CAFs was abundant. Notably, the other two ERs, ER $\alpha$ and ER $\beta$, were not detected by immunostaining or quantitative RT-PCR (Fig. 2A and B), consistent with a previous report (Madeo \& Maggiolini 2010).

\section{$E_{2}, G 1$, and TAM stimulate GPER response in breast CAFs}

$\mathrm{E}_{2}$ and TAM have been recognized as agonists of GPER, while G1 has been identified as a selective agonist (Wang et al. 2010, Prossnitz \& Barton 2011). The xCELLigence system has been demonstrated to be reliable and sensitive for the analysis of GPCR activation in living cells (Scott \& Peters 2010). To confirm the effect of $E_{2}, G 1$, and TAM on GPER in breast CAFs, GPCR activation was monitored intensity and percentage of positive-staining cells, the expression of GPER in epithelium cells was ranked as one of four grades, $+++(A),++(C)$, $+(E),-(G)$. Immunopositivity was detected in arterial endothelial cells and smooth muscle cells (I, star in J). Scale bars: $50 \mu \mathrm{m}$.

dynamically using the xCELLigence system following the administration of these agonists. $\mathrm{E}_{2}, \mathrm{G} 1$, and TAM stimulated transient and dose-dependent cell index increases within $1 \mathrm{~h}$, with peaking being observed at $1.58 \pm 0.21,1.29 \pm 0.11$, and $1.31 \pm 0.09$ respectively. These responses were eliminated by pretreatment with the GPER-specific antagonist G15 (Fig. 3A).

$\mathrm{Ca}^{2+}$ modulation has been reported to be correlated with GPER stimulation (Pietras et al. 2005) and therefore has been utilized as a sensor of GPER activation in early studies (Revankar et al. 2005). We monitored intracellular $\mathrm{Ca}^{2+}$ modulation by labeling laser scanning spectral confocal microscopy analysis of the Fluo-3 AM probe in CAFs. Within $30 \mathrm{~s}, \mathrm{E}_{2}(1 \mu \mathrm{M}), \mathrm{G} 1(1 \mu \mathrm{M})$, and TAM $(1 \mu \mathrm{M})$ enhanced fluorescence intensity (fold changes: 1.41 \pm $0.12,1.29 \pm 0.08$, and $1.26 \pm 0.09$, respectively, relative to the baseline), indicating that these agonists stimulated intracellular $\mathrm{Ca}^{2+}$ modulation. Similarly, G15 pretreatment blocked the effects on intercellular $\mathrm{Ca}^{2+}$ stimulated by $\mathrm{E}_{2}, \mathrm{G} 1$, and TAM (Fig. 3B).

It has been demonstrated that GPER induces ERK1/2 phosphorylation in response to $\mathrm{E}_{2}$ in breast cancer cells (Filardo et al. 2000). We also observed that $\mathrm{E}_{2}(1 \mu \mathrm{M}), \mathrm{G} 1$ $(1 \mu \mathrm{M})$, and TAM $(1 \mu \mathrm{M})$ stimulated ERK1/2 phosphorylation (fold changes: $1.82 \pm 0.22,1.60 \pm 0.19$, and $1.59 \pm 0.21$, respectively, relative to the control). Moreover, G15 pretreatment inhibited ERK1/2 activation induced by GPER ligands in breast CAFs (Fig. 3C).

Published by Bioscientifica Ltd. 


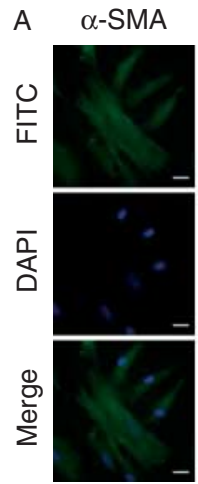

FAP
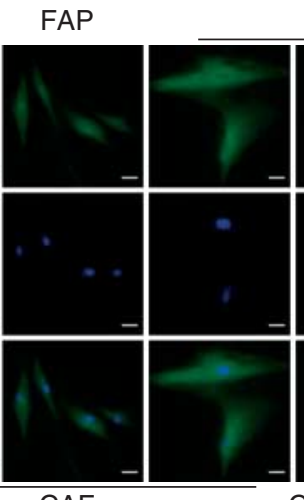

GPER
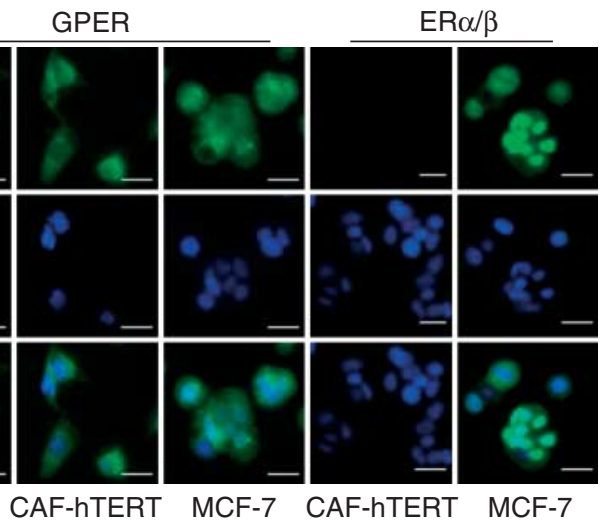

B

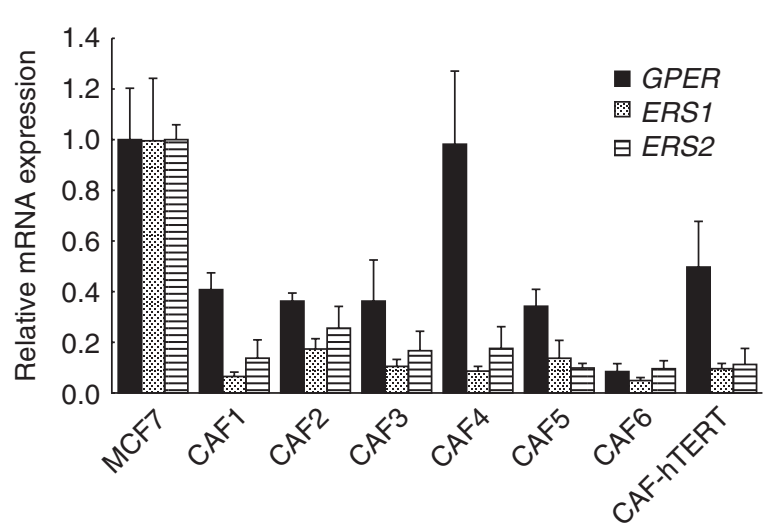

\section{Figure 2}

GPER is expressed in primary and immortalized breast CAFs. (A) CAFs were identified by immunofluorescent staining with $\alpha$-SMA and FAP. ERs were detected in primary breast CAFs, immortalized CAFs (CAF-hTERT), and MCF-7 cells as positive controls. Scale bars: $25 \mu \mathrm{m}$. (B) ER mRNA expression was

Although GPER was also detected in fibroblasts isolated from normal breast tissues, no significant effects of $E_{2}, G 1$, and TAM were observed in the aforementioned assays (Supplementary Figs 2 and 3, see section on supplementary data given at the end of this article).

\section{$E_{2}, G 1$, and TAM promote GPER-mediated proliferation in breast CAFs}

The role of GPER in CAF proliferation was examined by the administration of $E_{2}, G 1$, and TAM, and cell viability was measured after treatment for 3 days. $E_{2}, G 1$, and TAM enhanced the proliferation of breast CAFs after culture for $72 \mathrm{~h}$ in a dose-dependent manner. Maximal proliferation of $162.7 \pm 12.1,155.8 \pm 6.9$, and $136.6 \pm 8.5 \%$ relative to the control was detected following treatment with $\mathrm{E}_{2}$ (10 nM), G1 $(1 \mu \mathrm{M})$, and TAM $(10 \mathrm{nM})$ respectively (Fig. 4A). G15 abolished these cell proliferative effects evaluated by quantitative real-time RT-PCR in primary CAFs, CAF-hTERT cells, and MCF-7 cells. Gene expression was normalized to GAPDH, and results are shown as fold changes of mRNA levels compared with MCF-7 cells. The data are shown as means \pm s.D. for three independent experiments.

(Fig. 4B). To confirm the role of GPER in these proliferative effects further, GPER was knocked down to $39 \%$ by specific siRNA transfection of CAFs (CAF-GPERi). Interestingly, none of the ligands stimulated significant proliferative effects in CAF-GPERi cells. Moreover, CAF-GPERi cell numbers were significantly less than CAF-GPER cell numbers following the administration of $E_{2}(10 \mathrm{nM}), \mathrm{G} 1$ $(1 \mu \mathrm{M})$, and TAM (10 nM) (Fig. 4B).

The GPER-mediated effect on cell-cycle progression was investigated. Mammary CAFs were synchronized by estrogen and serum withdrawal and then treated with $\mathrm{E}_{2}$ (10 nM), G1 (1 $\mu \mathrm{M})$, and TAM (10 nM) for $24 \mathrm{~h}$ followed by PI staining and flow cytometry. The administration of $\mathrm{E}_{2}$, G1, and TAM significantly increased the proportion of S-phase CAFs from $13.4 \pm 3.2 \%$ to $26.9 \pm 6.8,24.7 \pm 5.4$, and $28.6 \pm 4.6 \%$. Importantly, both G15 pretreatment and GPER knockdown blocked the accumulation induced by $\mathrm{E}_{2}, \mathrm{G} 1$, and TAM (Fig. 4C).

Published by Bioscientifica Ltd. 
A
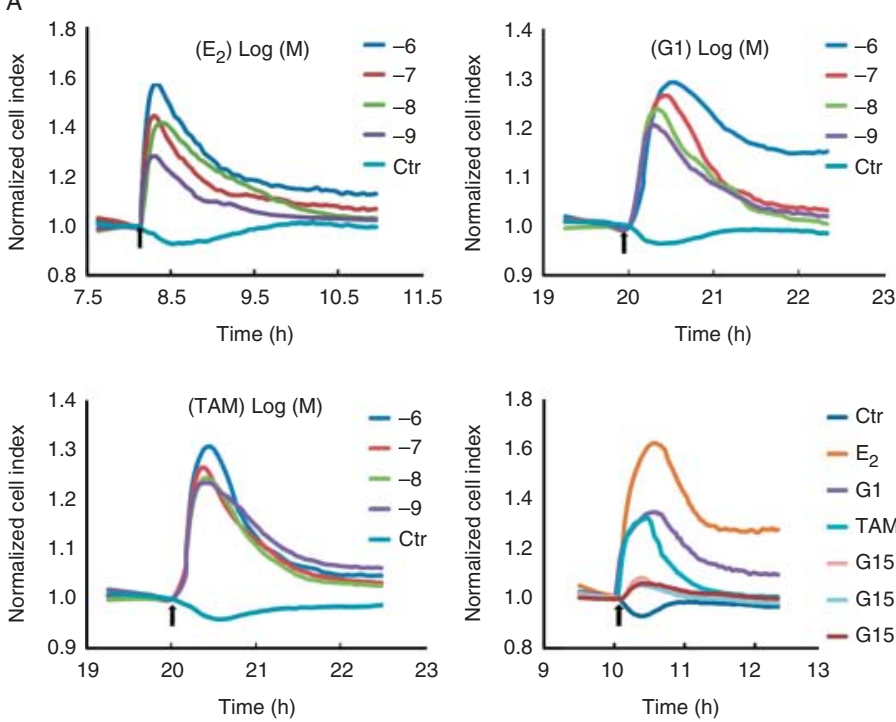

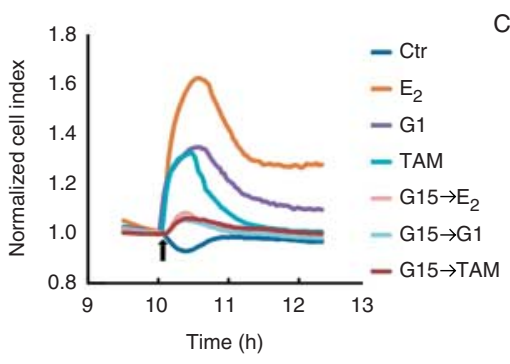

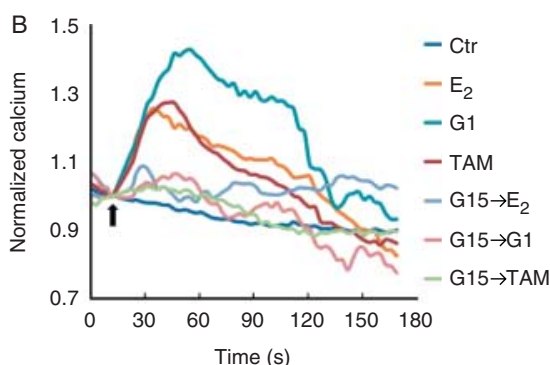

C

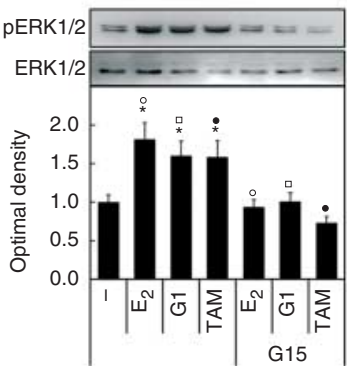

\section{Figure 3}

GPER is activated by $E_{2}, G 1$, and TAM in breast CAFs. (A) Cell index was monitored dynamically using the xCELLigence system following the administration of $E_{2}, G_{1}$, and TAM (concentrations as indicated or $1 \mu \mathrm{M}$ for all the three agents) at the indicated time (arrow) with or without pretreatment with $\mathrm{G} 15(1 \mu \mathrm{M})$. (B) $\mathrm{Ca}^{2+}$ labeled with the Fluo-3/AM probe was monitored dynamically by laser scanning spectral confocal microscopy. $\mathrm{E}_{2}(10 \mathrm{nM}), \mathrm{G} 1(1 \mu \mathrm{M})$, and TAM $(10 \mathrm{nM})$ were added at the indicated time

\section{GPER/EGFR/ERK pathway is involved in TAM-induced CAF proliferation}

As has been mentioned previously, GPER stimulation is involved in the transactivation of EGFR/ERK signaling and PI3K modulation in breast cancer cells (Filardo et al. 2002, Revankar et al. 2005). In this study, G15 (selective GPER antagonist), AG, U0126, and WM (inhibitors of EGFR, ERK1/2, and PI3K respectively) were used to evaluate the role of these pathways in GPER-mediated proliferation and cell-cycle changes in breast CAFs. G15, AG, and U0126 significantly inhibited the proliferation induced in CAFs by G1, TAM (Fig. 5A), and $\mathrm{E}_{2}$ (data not shown). WM treatment had no significant influence on CAF proliferation (Fig. 5A). Similar trends were observed for the accumulation of S-phase cells in response to G1, TAM (Fig. 5B), and $\mathrm{E}_{2}$ (data not shown). As a sensor of GPER/EGFR/ERK signaling activation, ERK1/2 phosphorylation was detected by immunoblotting. As expected, G15, AG, and U0126 significantly reduced ERK1/2 phosphorylation induced by G1, TAM (Fig. 5C), and $\mathrm{E}_{2}$ (data not shown) in CAFs. However, WM treatment had no significant influence on ERK1/2 phosphorylation in CAFs (Fig. 5C). Moreover, these GPER ligands did not enhance ERK phosphorylation in CAF-GPERi cells (Fig. 5D). (arrow) with or without G15 $(1 \mu \mathrm{M})$ pretreatment. (C) CAFs were treated with $E_{2}(10 \mathrm{nM}), \mathrm{G} 1(1 \mu \mathrm{M})$, and TAM $(10 \mathrm{nM})$ for $15 \mathrm{~min}$, with or without G15 $(1 \mu \mathrm{M})$ pretreatment. Cell extracts were used for immunoblotting analysis of total and phosphorylated ERK1/2. Results are shown as fold changes in optimal density compared with the control $(-)$. ${ }^{\star} P<0.05$, vs control; open square, open cirlce, and filled circle, $P<0.05$, between the two marked groups.

\section{GPER is involved in TAM-induced $E_{2}$ production}

CAFs are known to be an important source of local estrogen in breast cancer (Yamaguchi \& Hayashi 2009). We tested the ability of CAFs to synthesize $\mathrm{E}_{2}$ in vitro. The substrate of $\mathrm{E}_{2}$, testosterone, was added to the CAF culture medium for $48 \mathrm{~h}$ before harvesting for $\mathrm{E}_{2}$ detection by chemiluminescence immunoassay. The administration of testosterone stimulated dose-dependent $\mathrm{E}_{2}$ production. Furthermore, at a dose of $10 \mathrm{mM}$ testosterone, the S-phase accumulation increased dramatically to $44 \pm 5.8 \%$ (vs $32.3 \pm 4.5 \%$ in the control), while the concentration of $\mathrm{E}_{2}$ increased to $1553 \pm 158 \mathrm{pg} / \mathrm{ml}$ (vs $74 \pm 11$ in the control) (Fig. 6A).

Increasing evidence indicates that GPER is involved in aromatase gene regulation and local estrogen production (Lin et al. 2009, van Duursen et al. 2011, Pupo et al. 2012). We evaluated the potential role of GPER and related signaling in $\mathrm{E}_{2}$ production in the breast microenvironment. Interestingly, GPER activation increased $\mathrm{E}_{2}$ production in breast CAFs. Treatment of CAFs with testosterone $(100 \mathrm{nM})$ stimulated the production of $286 \pm 36 \mathrm{pg} / \mathrm{ml}$ (vs $73 \pm 14 \mathrm{pg} / \mathrm{ml}$ in the control) of $\mathrm{E}_{2}$ after cultivation for $48 \mathrm{~h}$. The administration of TAM $(10 \mathrm{nM})$ and $\mathrm{G} 1 \quad(1 \mu \mathrm{M})$ further increased the

Published by Bioscientifica Ltd 

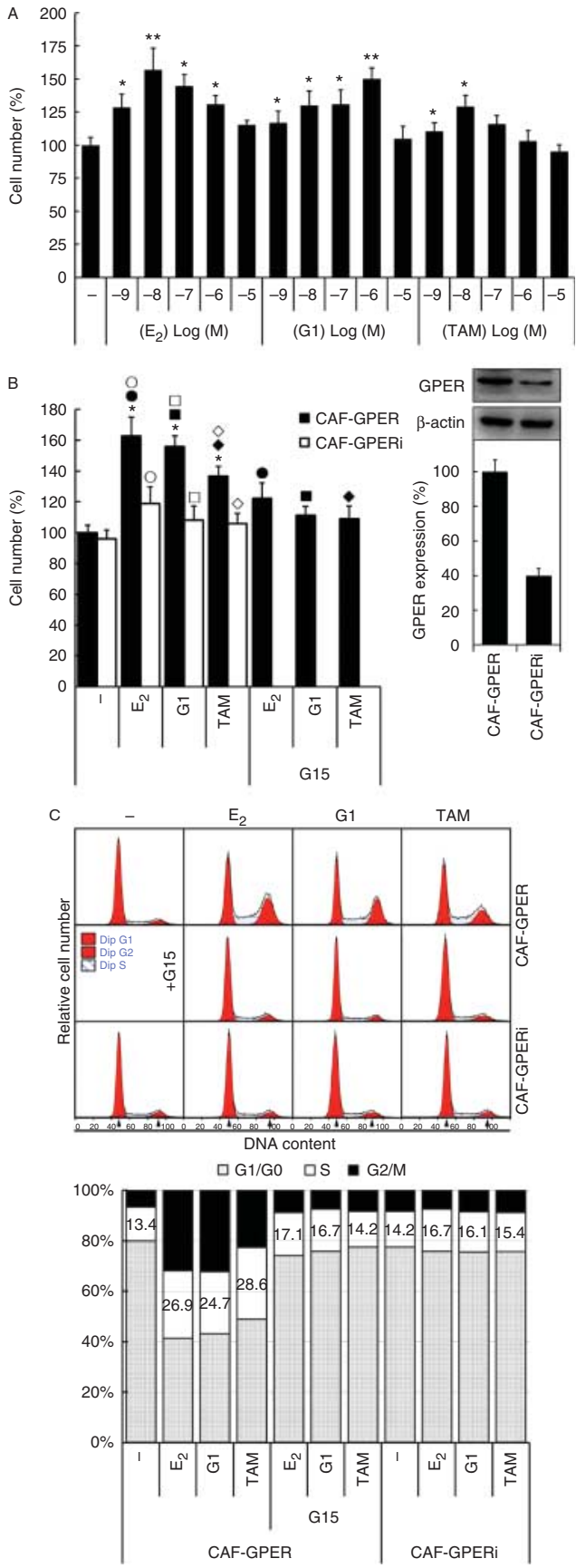

Figure 4

The EGFR/ERK axis is involved in GPER-mediated proliferation in breast CAFs. (A and B) Synchronized cells were cultured with $E_{2}$ (concentrations as indicated or $10 \mathrm{nM}$ ), G1 (concentrations as indicated or $1 \mu \mathrm{M}$ ), or TAM (concentrations as indicated or $10 \mathrm{nM}$ ) for $72 \mathrm{~h}$, with or without G15 pretreatment $(1 \mu \mathrm{M})$. Cell viability was then measured using Cell Counting Kit-8. ${ }^{*} P<0.05$ vs control; $* * P<0.01$ vs control; filled circles, filled squares, filled diamonds, open circles, open squares, and open diamonds, $P<0.05$, between the two marked groups. (C) Synchronized cells were cultured with $\mathrm{E}_{2}(10 \mathrm{nM}), \mathrm{G} 1(1 \mu \mathrm{M})$, and TAM $(10 \mathrm{nM})$ in the presence or absence of $\mathrm{G} 15$ $(1 \mu \mathrm{M})$ for $24 \mathrm{~h}$. The cells were then stained with propidium iodide and cell-cycle distribution was analyzed by flow cytometry. A full colour version of this figure is available via http://dx.doi.org/10.1530/ERC-13-0237. concentration of $\mathrm{E}_{2}$ to $419 \pm 60$ and $541 \pm 69 \mathrm{pg} / \mathrm{ml}$ respectively. This enhancement was inhibited by GPER knockdown and G15, AG, and U0126 administration but not by WM administration (Fig. 6C). These data were paralleled by the effects of GPER interference and G15, AG, U0126, and WM on cell viability when administered under identical conditions (Fig. 5B). Hence, we attempted to verify whether this phenomenon was caused by GPERmediated proliferation or GPER-induced aromatase expression in breast CAFs (Lin et al. 2009, van Duursen et al. 2011, Pupo et al. 2012). As expected, culturing with TAM $(10 \mathrm{nM})$ and $\mathrm{G} 1(1 \mu \mathrm{M})$ for $18 \mathrm{~h}$ induced CYP19A1 gene expression (fold changes: $3.4 \pm 0.6$ and $3.8 \pm 1.0$, respectively, vs the control) in CAFs, and this effect was blocked by GPER interference and G15, AG, and U0126 but not by WM (Fig. 6D).

\section{Discussion}

Estrogens play an important role in breast cancer development. ER $\alpha$ is widely accepted as a target for endocrine therapy of breast cancer, and a well-known SERM, TAM, provides considerable benefits for patients with breast cancer at different stages. However, acquired TAM resistance in ER $\alpha$-positive breast cancer cells has become a significant challenge in its clinical application. Recently, TAM resistance has been reported to be correlated with the expression of the novel ER, GPER (Ignatov et al. 2010, 2011). In the present study, we demonstrated that GPER is expressed in the stromal fibroblasts of primary breast cancer tissues and CAFs isolated from tumor tissues. TAM, in addition to $E_{2}$ and the GPER agonist G1, promoted proliferation, cell-cycle progression, and $\mathrm{E}_{2}$ production via the GPER/EGFR/ERK axis in breast CAFs, providing novel insights into the GPER-mediated CAF-dependent mechanism of TAM resistance in breast cancer.

GPER was first detected as a GPCR gene in breast cancer cell lines as well as in primary breast cancer in 1997 (Carmeci et al. 1997). Subsequently, several examples of GPER expression in breast cancer have been reported. Filardo et al. (2006) conducted an immunohistochemical analysis of the distribution of GPER in 361 cases of breast cancer and correlated GPER with the expression of ER $\alpha$, the progestin receptor, and human EGFR2 as well as tumor size and the presence of metastasis. However, results obtained in other studies were not consistent with these observations ( $\mathrm{Tu}$ et al. 2009, Arias-Pulido et al. 2010, Ignatov et al. 2011). In the present study, the presence of GPER in cancer cells was exclusively correlated with ER $\alpha$

Published by Bioscientifica Ltd. 


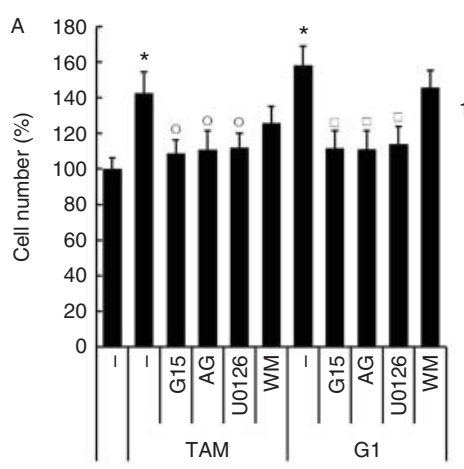
B

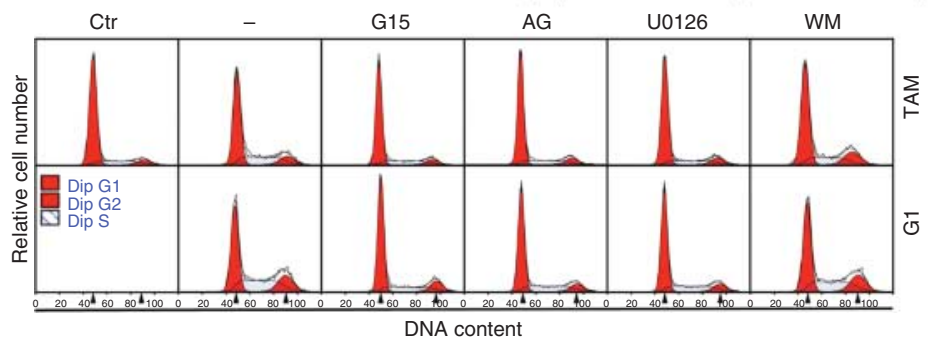

C
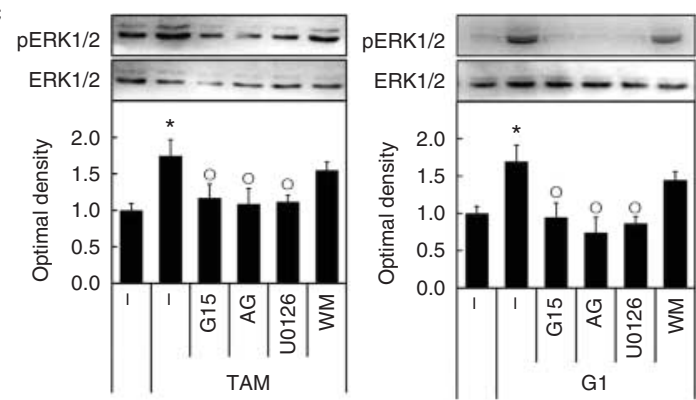

D

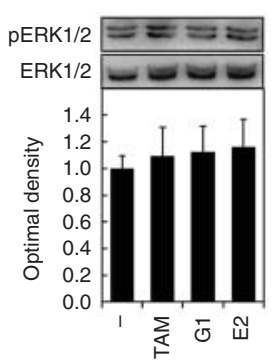

\section{Figure 5}

The EGFR/ERK axis is involved in GPER-mediated proliferation in breast CAFs. (A) Synchronized cells were cultured with G1 $(1 \mu \mathrm{M})$ or TAM (10 nM) in the presence or absence of G15 $(1 \mu \mathrm{M}), \mathrm{AG}(10 \mu \mathrm{M}), \mathrm{U} 0126(10 \mu \mathrm{M})$, and WM $(10 \mu \mathrm{M})$ for $72 \mathrm{~h}$. Cell viability was measured using Cell Counting Kit-8. $* P<0.05$ vs control; open circles, $P<0.05$ vs TAM group; and open squares, $P<0.05$ vs $G 1$ group. (B) Synchronized cells were cultured with $\mathrm{G} 1(1 \mu \mathrm{M})$ or TAM $(10 \mathrm{nM})$ in the presence or absence of G15 $(1 \mu \mathrm{M}), \mathrm{AG}(10 \mu \mathrm{M}), \mathrm{U} 0126$ $(10 \mu \mathrm{M})$, and WM $(10 \mu \mathrm{M})$ for $24 \mathrm{~h}$. The cells were then stained with propidium iodide and cell-cycle distribution was analyzed by flow cytometry. (C) The cells (CAF-GPER) were treated with G1 $(1 \mu \mathrm{M})$ or TAM
$(10 \mathrm{nM})$ for $15 \mathrm{~min}$, with or without G15 pretreatment $(1 \mu \mathrm{M})$, AG $(10 \mu \mathrm{M})$, U0126 $(10 \mu \mathrm{M})$, and WM $(10 \mu \mathrm{M})$. Cell extracts were used for immunoblotting analysis of phosphorylated and total ERK1/2. Results are shown as fold changes in optimal density compared with the control. ${ }^{*} P<0.05$ vs control and open circles, $P<0.05$ vs $\mathrm{G} 1$ and TAM group. (D) The cells (CAF-GPERi) were treated with $E_{2}(10 \mathrm{nM}), \mathrm{G} 1(1 \mu \mathrm{M})$, and TAM $(10 \mathrm{nM})$ for $15 \mathrm{~min}$. Cell extracts were used for immunoblotting analysis of phosphorylated and total ERK1/2. Results are shown as fold changes in optimal density compared with the control. A full colour version of this figure is available via http://dx.doi.org/10.1530/ERC-13-0237. expression (Table 2). Additionally, the co-expression of GPER and ER $\alpha$ in carcinoma cells was found in $41.1 \%$ of all samples, which is in accordance with previous reports (Filardo et al. 2006, Tu et al. 2009, Ignatov et al. 2011). The presence of $\mathrm{ER} \alpha$ is considered to be a definite indication for the administration of TAM, which is a well-characterized agonist of GPER. TAM administration has been shown to stimulate GPER in these patients, resulting in proliferative effects (Lin et al. 2009, Madeo \& Maggiolini 2010, Pupo et al. 2012, Vivacqua et al. 2012). In vitro, TAM has been reported to promote proliferation via sensitivity-enhanced GPER/EGFR/MAPK signaling in TAM-resistant MCF-7 cells (Ignatov et al. 2010, Peralta et al. 2010). In recent follow-up studies, GPER has been shown to be correlated with reduced relapse-free survival in patients undergoing TAM treatment (Ignatov et al. 2011). These observations implicate GPER in breast carcinoma TAM resistance, although this remains to be confirmed.

GPER has been detected in stromal inflammatory cells, myoepithelium, and fibroblasts in addition to tumor cells of primary breast cancer (Arias-Pulido et al. 2010), although an analysis of its expression has not been reported previously. In this study, positive GPER staining was observed in stromal fibroblasts, smooth muscle cells, and arterial endothelial cells, all of which are recognized as origins of CAFs (Karnoub et al. 2007, Xing et al. 2010, Cirri \& Chiarugi 2012). Considering the important role of both estrogen and CAFs in breast cancer development, we correlated GPER expression in stromal fibroblasts with the clinicopathological determinants of breast cancer. Although no significant association was found, GPER expression was definitely detected in stromal fibroblasts of $41.8 \%$ of the samples (Table 2), implying a GPER-mediated CAFdependent estrogenic effect in tumor microenvironment.

Estrogens play an important role in the development of mammary glands and associated carcinomas. In healthy women, the extracellular matrix of breast tissue, in addition to the mammary epithelial cells, undergoes cyclic changes with each menstrual cycle (Arendt et al. 2010). Although stromal ER $\alpha$ has been demonstrated to be critical for breast

Published by Bioscientifica Ltd. 

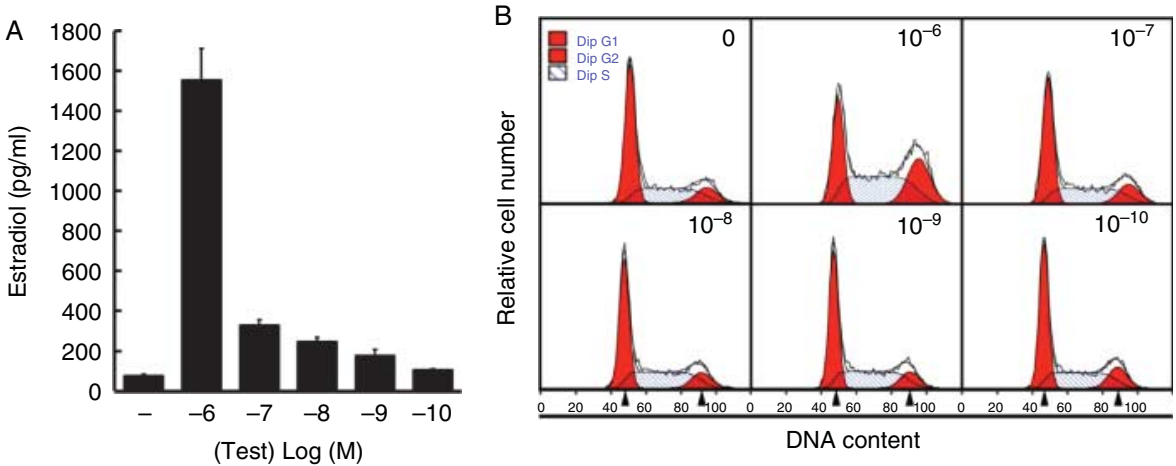

DNA content
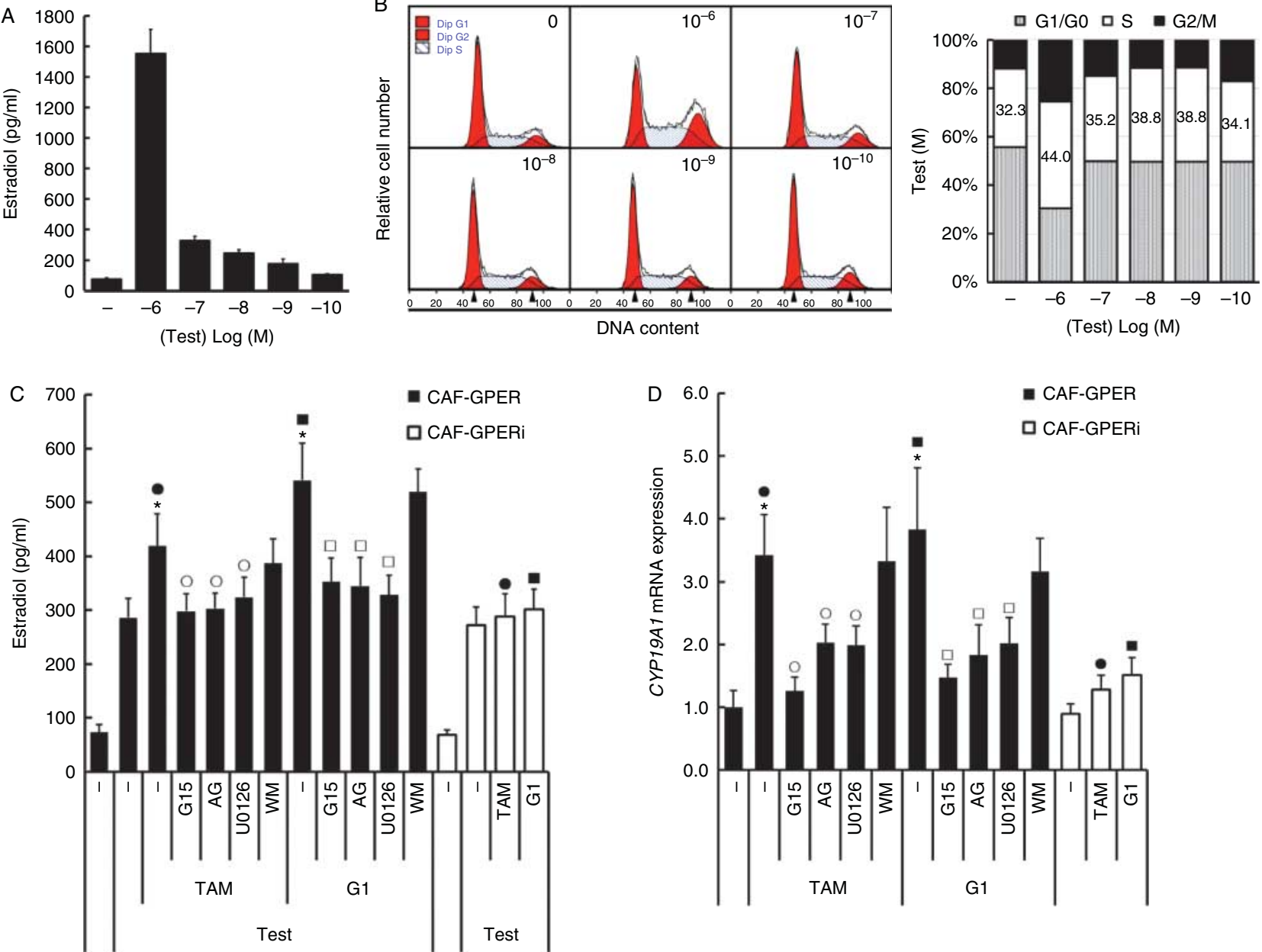

Figure 6

Effect of GPER/EGFR/ERK signaling on estradiol $\left(E_{2}\right)$ production in breast CAFs. (A and B) Testosterone was added to CAF culture medium for $48 \mathrm{~h}$ before harvesting for $E_{2}$ detection by chemiluminescence immunoassay. Cell-cycle distribution was analyzed by flow cytometry. (C) Testosterone $(100 \mathrm{nM})$ was added to breast CAF culture medium and cells were cultured with $\mathrm{G} 1(1 \mu \mathrm{M})$ or TAM $(10 \mathrm{nM})$ in the presence or absence of G15 $(1 \mu \mathrm{M})$, AG $(10 \mu \mathrm{M})$, U0126 $(10 \mu \mathrm{M})$, and WM $(10 \mu \mathrm{M})$ for $48 \mathrm{~h}$. The medium was harvested for $E_{2}$ detection by chemiluminescence immunoassay. ${ }^{*} P<0.05$ vs cells treated with only testosterone; open circles, $P<0.05$ vs TAM group; open squares, $P<0.05$ vs $G 1$ group; and filled circles and filled squares,

development in mice (Mueller et al. 2002), studies focusing on ERs and estrogen effects in tumor-associated stroma are rare. Recently, GPER has been demonstrated to be a unique ER mediating $\mathrm{E}_{2}$-stimulated proliferation and migration of breast CAFs (Madeo \& Maggiolini 2010). Subsequently, GPER/EGFR/ERK signaling has been claimed to upregulate the expression of EGR1, CTGF, C-FOS, and cyclin D1, resulting in proliferation enhancement in mammary CAFs (Pupo et al. 2012, Vivacqua et al. 2012). Interactions between estrogen and growth factors were delineated

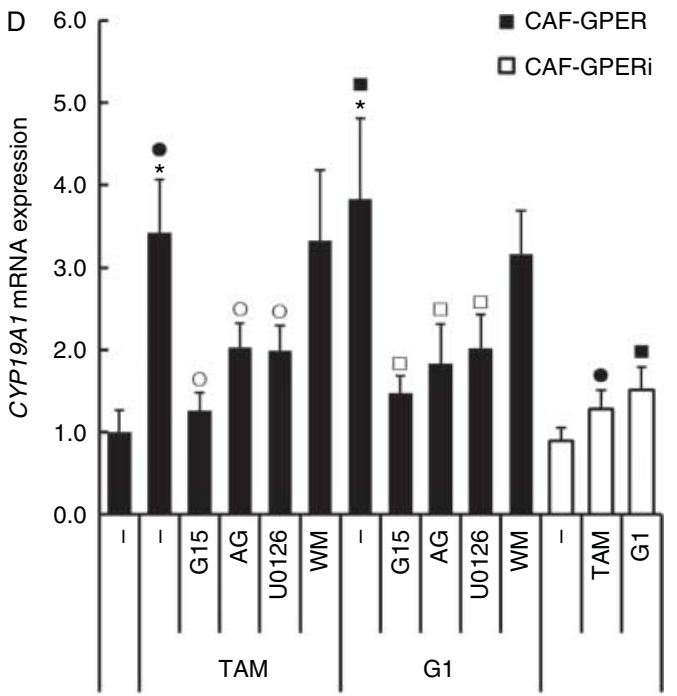

$P<0.05$, between the two marked groups. (D) Synchronized cells were cultured with $\mathrm{G} 1(1 \mu \mathrm{M})$ or TAM $(10 \mathrm{nM})$ in the presence or absence of G15 $(1 \mu \mathrm{M}), \mathrm{AG}(10 \mu \mathrm{M}), \mathrm{U} 0126(10 \mu \mathrm{M})$, and WM $(10 \mu \mathrm{M})$ for $18 \mathrm{~h}$. Total RNA was then extracted to perform quantitative RT-PCR analysis of CYP19A1 mRNA expression. Gene expression was normalized to GAPDH, and results are shown as fold changes of mRNA levels compared with the control. $\star P<0.05$ vs control; open circles, $P<0.05$ vs TAM group; open squares, $P<0.05$ vs $\mathrm{G} 1$ group; and filled circles and filled squares, $P<0.05$, between the two marked groups. A full colour version of this figure is available via http://dx.doi.org/10.1530/ERC-13-0237.

decades ago (Pietras et al. 2005). GPER is thought to be largely responsible for this crosstalk, as it has been demonstrated to employ the EGFR/ERK pathway as its predominant signaling pathway, and growth factors including EGF, CTGF, transforming growth factor $\alpha / \beta$, and insulin-like growth factor have been observed to regulate GPER expression or be regulated by GPER activation (Filardo 2002, Filardo et al. 2002, Vivacqua et al. 2009, Madeo \& Maggiolini 2010, De Marco et al. 2012). Similarly, we demonstrated in this study that

Published by Bioscientifica Ltd. 
GPER/EGFR/ERK signal transduction mediates $\mathrm{E}_{2}$-induced proliferation in breast CAFs, based on the observation that G1 induced similar proliferative and cell-cycle promotion that was blocked not only by GPER interference but also by G15, AG, and U0126 administration. These observations revealed the CAF-dependent estrogenic effects on breast cancer microenvironment.

Interestingly, we demonstrated that TAM also stimulated the proliferation of CAFs via the GPER/EGFR/ERK pathway in this study (Fig. 5), and its metabolite 4-hydroxytamoxifen has also been shown to promote breast CAF growth in a previous study (Vivacqua et al. 2012). Notably, $\sim 40 \%$ of ER $\alpha$-positive tumors expressed GPER in stromal fibroblasts in our study (Table 2). CAFs are promoters of tumor growth; therefore, it can be suggested that the anti-estrogen effect of TAM in tumor cells is negated by TAM-induced proliferation in CAFs, resulting in acquired TAM resistance in these patients. Recently, GPER expression in breast cancer cells has been reported to be correlated with poorer relapse-free survival only in patients treated with TAM, but tended to be a favorable factor in patients who did not receive TAM therapy (Ignatov et al. 2011). A potential role for GPER expression in CAFs in this bidirectional effects is indicated by the detection of stromal fibroblast GPER expression in $40 \%$ of ER $\alpha$-positive tumors in our study. Thus, more follow-up data are required in addition to an analysis of GPER expression in stromal fibroblasts and epithelium as determinants for TAM administration in breast cancer patients.

CAFs are an important source of local estrogen, which is an important mediator of breast cancer progression (Yamaguchi \& Hayashi 2009). As a key enzyme involved in estrogen synthesis, aromatase has become a paradigm target of endocrine therapy in breast cancer patients. Intriguingly, GPER has been reported to be correlated with aromatase gene upregulation directly or indirectly in previous studies (van Duursen et al. 2011, Pupo et al. 2012). An analog and a metabolite of TAM have been demonstrated to promote aromatase gene expression via GPER activation in endometrial cancer cells (Lin et al. 2009). Furthermore, genistein, a well-recognized GPER agonist, has been reported to increase breast-cancerassociated aromatase expression and activity in vitro (van Duursen et al. 2011). In the present study, TAM and $\mathrm{G} 1$ increased both CYP19A1 mRNA and $\mathrm{E}_{2}$ production in CAFs, and this effect was dependent on GPER/ EGFR/ERK pathway signaling. Taken together, these observations indicate that GPER in breast CAFs is involved in the increased local production of $E_{2}$, thus presenting a feed-forward loop model that has been postulated to contribute to TAM resistance in breast cancer patients.

The role of GPER in breast CAFs warrants further investigation following its detection in stromal fibroblasts in breast cancer tissues. Furthermore, we confirmed previous reports that the GPER/EGFR/ERK pathway contributes to the proliferation of breast CAFs (Madeo \& Maggiolini 2010, Pupo et al. 2012, Vivacqua et al. 2012). Thus, our data provide new insights into estrogenic effects on tumor microenvironment. More importantly, TAM, which is commonly accepted to be a SERM for breast cancer patients, was shown to stimulate proliferation and $\mathrm{E}_{2}$ production in breast CAFs. Hence, GPER is implicated in TAM resistance in a CAF-dependent manner. As such, GPER expression in stromal fibroblasts would be considered a contra-indicator of TAM application or additional therapy targeting GPER signaling ought to be offered in the future.

\section{Supplementary data}

This is linked to the online version of the paper at http://dx.doi.org/10.1530/ ERC-13-0237.

\section{Declaration of interest}

The authors declare that there is no conflict of interest that could be perceived as prejudicing the impartiality of the research reported.

\section{Funding}

This study was supported by the National Natural Science Foundation of China (NSFC 81372398, NSFC 81072149, and NSFC 81072147).

\section{Acknowledgements}

The authors thank Prof. Hua Tang from the Key Laboratory of Molecular Biology for Infectious Diseases, Ministry of Education Medicine, Chongqing Medical University, for his kind help.

\section{References}

Ahn S, Cho J, Sung J, Lee JE, Nam SJ, Kim KM \& Cho EY 2012 The prognostic significance of tumor-associated stroma in invasive breast carcinoma. Tumour Biology 33 1573-1580. (doi:10.1007/s13277-012-0411-6)

Arendt LM, Rudnick JA, Keller PJ \& Kuperwasser C 2010 Stroma in breast development and disease. Seminars in Cell \& Developmental Biology 21 11-18. (doi:10.1016/j.semcdb.2009.10.003)

Arias-Pulido H, Royce M, Gong Y, Joste N, Lomo L, Lee SJ, Chaher N, Verschraegen C, Lara J, Prossnitz ER et al. 2010 GPR30 and estrogen receptor expression: new insights into hormone dependence of inflammatory breast cancer. Breast Cancer Research and Treatment 123 51-58. (doi:10.1007/s10549-009-0631-7)

Published by Bioscientifica Ltd 
Barcellos-Hoff MH \& Ravani SA 2000 Irradiated mammary gland stroma promotes the expression of tumorigenic potential by unirradiated epithelial cells. Cancer Research 60 1254-1260.

Carmeci C, Thompson DA, Ring HZ, Francke U \& Weigel RJ 1997 Identification of a gene (GPR30) with homology to the G-protein-coupled receptor superfamily associated with estrogen receptor expression in breast cancer. Genomics 45 607-617. (doi:10.1006/geno.1997.4972)

Cirri P \& Chiarugi P 2012 Cancer-associated-fibroblasts and tumour cells: a diabolic liaison driving cancer progression. Cancer Metastasis Reviews 31 195-208. (doi:10.1007/s10555-011-9340-x)

De Marco P, Bartella V, Vivacqua A, Lappano R, Santolla MF, Morcavallo A, Pezzi V, Belfiore A \& Maggiolini M 2012 Insulin-like growth factor-I regulates GPER expression and function in cancer cells. Oncogene 32 678-688. (doi:10.1038/onc.2012.97)

van Duursen MB, Nijmeijer SM, de Morree ES, de Jong PC \& van den Berg M 2011 Genistein induces breast cancer-associated aromatase and stimulates estrogen-dependent tumor cell growth in in vitro breast cancer model. Toxicology 289 67-73. (doi:10.1016/j.tox.2011.07.005)

Filardo EJ 2002 Epidermal growth factor receptor (EGFR) transactivation by estrogen via the G-protein-coupled receptor, GPR30: a novel signaling pathway with potential significance for breast cancer. Journal of Steroid Biochemistry and Molecular Biology 80 231-238. (doi:10.1016/ S0960-0760(01)00190-X)

Filardo EJ, Quinn JA, Bland KI \& Frackelton AR Jr 2000 Estrogen-induced activation of Erk-1 and Erk-2 requires the G protein-coupled receptor homolog, GPR30, and occurs via trans-activation of the epidermal growth factor receptor through release of HB-EGF. Molecular Endocrinology 14 1649-1660. (doi:10.1210/mend.14.10.0532)

Filardo EJ, Quinn JA, Frackelton AR Jr \& Bland KI 2002 Estrogen action via the G protein-coupled receptor, GPR30: stimulation of adenylyl cyclase and cAMP-mediated attenuation of the epidermal growth factor receptor-to-MAPK signaling axis. Molecular Endocrinology 16 70-84. (doi:10.1210/mend.16.1.0758)

Filardo EJ, Graeber CT, Quinn JA, Resnick MB, Giri D, DeLellis RA, Steinhoff MM \& Sabo E 2006 Distribution of GPR30, a seven membrane-spanning estrogen receptor, in primary breast cancer and its association with clinicopathologic determinants of tumor progression. Clinical Cancer Research 12 6359-6366. (doi:10.1158/1078-0432.CCR06-0860)

Hoshino A, Ishii G, Ito T, Aoyagi K, Ohtaki Y, Nagai K, Sasaki H \& Ochiai A 2011 Podoplanin-positive fibroblasts enhance lung adenocarcinoma tumor formation: podoplanin in fibroblast functions for tumor progression. Cancer Research 71 4769-4779. (doi:10.1158/0008-5472.CAN-10-3228)

Hu M, Yao J, Carroll DK, Weremowicz S, Chen H, Carrasco D, Richardson A, Violette S, Nikolskaya T, Nikolsky Y et al. 2008 Regulation of in situ to invasive breast carcinoma transition. Cancer Cell 13 394-406. (doi:10.1016/j.ccr.2008.03.007)

Ignatov A, Ignatov T, Roessner A, Costa SD \& Kalinski T 2010 Role of GPR30 in the mechanisms of tamoxifen resistance in breast cancer MCF-7 cells. Breast Cancer Research and Treatment 123 87-96. (doi:10.1007/ s10549-009-0624-6)

Ignatov A, Ignatov T, Weissenborn C, Eggemann H, Bischoff J, Semczuk A, Roessner A, Costa SD \& Kalinski T 2011 G-protein-coupled estrogen receptor GPR30 and tamoxifen resistance in breast cancer. Breast Cancer Research and Treatment 128 457-466. (doi:10.1007/s10549011-1584-1)

Karnoub AE, Dash AB, Vo AP, Sullivan A, Brooks MW, Bell GW, Richardson AL, Polyak K, Tubo R \& Weinberg RA 2007 Mesenchymal stem cells within tumour stroma promote breast cancer metastasis. Nature 449 557-563. (doi:10.1038/nature06188)

de Kruijf EM, van Nes JG, van de Velde CJ, Putter H, Smit VT, Liefers GJ, Kuppen PJ, Tollenaar RA \& Mesker WE 2011 Tumor-stroma ratio in the primary tumor is a prognostic factor in early breast cancer patients, especially in triple-negative carcinoma patients. Breast Cancer Research and Treatment 125 687-696. (doi:10.1007/s10549-010-0855-6)
Leonard AP, Appleton KM, Luttrell LM \& Peterson YK 2013 A high-content, live-cell, and real-time approach to the quantitation of ligand-induced $\beta$-arrestin2 and class A/class B GPCR mobilization. Microscopy and Microanalysis 19 150-170. (doi:10.1017/S1431927612014067)

Lin BC, Suzawa M, Blind RD, Tobias SC, Bulun SE, Scanlan TS \& Ingraham HA 2009 Stimulating the GPR30 estrogen receptor with a novel tamoxifen analogue activates SF-1 and promotes endometrial cell proliferation. Cancer Research 69 5415-5423. (doi:10.1158/0008-5472. CAN-08-1622)

Liu M, Sakamaki T, Casimiro MC, Willmarth NE, Quong AA, Ju X, Ojeifo J, Jiao X, Yeow WS, Katiyar S et al. 2010 The canonical NF-kB pathway governs mammary tumorigenesis in transgenic mice and tumor stem cell expansion. Cancer Research 70 10464-10473. (doi:10.1158/ 0008-5472.CAN-10-0732)

Madeo A \& Maggiolini M 2010 Nuclear alternate estrogen receptor GPR30 mediates $17 \beta$-estradiol-induced gene expression and migration in breast cancer-associated fibroblasts. Cancer Research 70 6036-6046. (doi:10.1158/0008-5472.CAN-10-0408)

Mueller SO, Clark JA, Myers PH \& Korach KS 2002 Mammary gland development in adult mice requires epithelial and stromal estrogen receptor $\alpha$. Endocrinology 143 2357-2365. (doi:10.1210/endo.143.6. 8836)

O'Dowd BF, Nguyen T, Marchese A, Cheng R, Lynch KR, Heng HH, Kolakowski LF Jr \& George SR 1998 Discovery of three novel G-protein-coupled receptor genes. Genomics 47 310-313. (doi:10.1006/ geno.1998.5095)

Owman C, Blay P, Nilsson C \& Lolait SJ 1996 Cloning of human cDNA encoding a novel heptahelix receptor expressed in Burkitt's lymphoma and widely distributed in brain and peripheral tissues. Biochemical and Biophysical Research Communications 228 285-292. (doi:10.1006/ bbrc.1996.1654)

Peralta EA, Rutz M \& Louis S 2010 GPR30 is an estrogen receptor in breast cancer that increases tamoxifen resistance. Journal of Surgical Research 158 335-336. (doi:10.1016/j.jss.2009.11.452)

Pietras RJ \& Szego CM 1975 Endometrial cell calcium and oestrogen action. Nature 253 357-359. (doi:10.1038/253357a0)

Pietras RJ, Levin ER \& Szego CM 2005 Estrogen receptors and cell signaling. Science 310 51-53 (author reply 51-53). (doi:10.1126/science.310. 5745.51)

Proia DA \& Kuperwasser C 2005 Stroma: tumor agonist or antagonist. Cell Cycle 4 1022-1025. (doi:10.4161/cc.4.8.1903)

Prossnitz ER \& Barton M 2011 The G-protein-coupled estrogen receptor GPER in health and disease. Nature Reviews. Endocrinology 7 715-726. (doi:10.1038/nrendo.2011.122)

Prossnitz ER \& Maggiolini M 2009 Mechanisms of estrogen signaling and gene expression via GPR30. Molecular and Cellular Endocrinology 308 32-38. (doi:10.1016/j.mce.2009.03.026)

Pupo M, Pisano A, Lappano R, Santolla MF, De Francesco EM, Abonante S, Rosano C \& Maggiolini M 2012 Bisphenol A induces gene expression changes and proliferative effects through GPER in breast cancer cells and cancer-associated fibroblasts. Environmental Health Perspectives 120 1177-1182. (doi:10.1289/ehp.1104526)

Revankar CM, Cimino DF, Sklar LA, Arterburn JB \& Prossnitz ER 2005 A transmembrane intracellular estrogen receptor mediates rapid cell signaling. Science 307 1625-1630. (doi:10.1126/science.1106943)

Sappino AP, Skalli O, Jackson B, Schurch W \& Gabbiani G 1988 Smooth-muscle differentiation in stromal cells of malignant and non-malignant breast tissues. International Journal of Cancer $\mathbf{4 1}$ 707-712. (doi:10.1002/ijc.2910410512)

Scott CW \& Peters MF 2010 Label-free whole-cell assays: expanding the scope of GPCR screening. Drug Discovery Today 15 704-716. (doi:10.1016/j.drudis.2010.06.008)

Tu G, Hu D, Yang G \& Yu T 2009 The correlation between GPR30 and clinicopathologic variables in breast carcinomas. Technology in Cancer Research \& Treatment 8 231-234.

Published by Bioscientifica Ltd. 
Vivacqua A, Lappano R, De Marco P, Sisci D, Aquila S, De Amicis F, Fuqua SA, Ando S \& Maggiolini M 2009 G protein-coupled receptor 30 expression is up-regulated by EGF and TGF $\alpha$ in estrogen receptor $\alpha$-positive cancer cells. Molecular Endocrinology 23 1815-1826. (doi:10.1210/me.2009-0120)

Vivacqua A, Romeo E, De Marco P, De Francesco EM, Abonante S \& Maggiolini M 2012 GPER mediates the Egr-1 expression induced by $17 \beta$-estradiol and 4-hydroxitamoxifen in breast and endometrial cancer cells. Breast Cancer Research and Treatment 133 1025-1035. (doi:10.1007/s10549-011-1901-8)

Wang D, Hu L, Zhang G, Zhang L \& Chen C 2010 G protein-coupled receptor 30 in tumor development. Endocrine 38 29-37. (doi:10.1007/ s12020-010-9363-z)
Xing F, Saidou J \& Watabe K 2010 Cancer associated fibroblasts (CAFs) in tumor microenvironment. Frontiers in Bioscience 15 166-179. (doi:10.2741/3613)

Yamaguchi Y \& Hayashi S 2009 Estrogen-related cancer microenvironment of breast carcinoma. Endocrine Journal 56 1-7. (doi:10.1507/endocri.K08E-099)

Zeisberg EM, Potenta S, Xie L, Zeisberg M \& Kalluri R 2007 Discovery of endothelial to mesenchymal transition as a source for carcinomaassociated fibroblasts. Cancer Research 67 10123-10128. (doi:10.1158/ 0008-5472.CAN-07-3127)

Zhao L, Sun Y, Hou Y, Peng Q, Wang L, Luo H, Tang X, Zeng Z \& Liu M 2012 MiRNA expression analysis of cancer-associated fibroblasts and normal fibroblasts in breast cancer. International Journal of Biochemistry \& Cell Biology 44 2051-2059. (doi:10.1016/j.biocel.2012.08.005)

Received in final form 23 January 2014

Accepted 30 January 2014

Made available online as an Accepted Preprint

30 January 2014
Published by Bioscientifica Ltd. 